\title{
Análise sobre condições de trabalho de Equipe de Saúde da Família, num contexto de vulnerabilidades, Manaus (AM)
}

\author{
Analysis on work conditions of Family Health Team in a context of \\ vulnerabilities, Manaus (AM)
}

Arlete Lima Simões ${ }^{\mathbf{1}}$ Carlos Machado de Freitas ${ }^{\mathbf{2}}$

RESUMO Este estudo tem o objetivo de descrever e analisar as condições de trabalho de uma Equipe de Saúde da Família, em contexto socioambiental vulnerável, a partir de um estudo de caso. Trata-se de um estudo de abordagem qualitativa, com observação participante, entrevistas e grupo focal. Os resultados revelaram que as vulnerabilidades do território em que atuam os profissionais impactam menos do que a infraestrutura inadequada das condições de trabalho, como a falta de materiais e equipamentos necessários para a produção de saúde no território, portanto, o ambiente interno das condições da unidade de saúde, revelou-se um fator de insatisfação, repercutindo de forma negativa no processo de trabalho da equipe.

PALAVRAS-CHAVE Saúde do trabalhador; Ambiente de trabalho; Territorialidade; Saúde da família.

ABSTRACT This study aims to describe and analyze the working conditions of a Family Health Team, in vulnerable socio-environmental context, from a case study. It is about a qualitative study approach, with participant observation, interviews and focus group. The results revealed that the vulnerabilities of the territory in which professionals work impact less than the inadequate infrastructure of working conditions, such as lack of materials and equipment necessary for the health production in the territory, therefore, the internal environment of the health unit conditions, proved to be a factor of dissatisfaction, reflecting negatively on the team work process.

Secretaria Municipal de Saúde (Semsa) - Manaus (AM), Brasil.

limarletes@gmail.com

2 Fundação Oswaldo Cruz (Fiocruz), Escola Nacional de Saúde Pública Sergio Arouca (Ensp), Centro de Estudos da Saúde do Trabalhador e Ecologia Humana (Cesteh) e Centro de Estudos e Pesquisas de Emergências e Desastres em Saúde (Cepedes) - Rio de Janeiro (RJ), Brasil. carlosmf@ensp.fiocruz.br

KEYWORDS Occupational health; Working environment; Territoriality; Family health. 


\section{Introdução}

O trabalho representa um componente importante para entender as relações sociais e seus possíveis impactos no cotidiano dos trabalhadores. No modelo baseado na Estratégia Saúde da Família (ESF), propõese o desenvolvimento de ações com equipes multiprofissionais, atuando em territórios específicos, cuja dinâmica socioambiental deve ser conhecida pelos trabalhadores no processo de produção do cuidado da população adscrita.

Dessa forma, a produção de saúde no território constitui um grande desafio para as equipes, pois estudos revelam que o desgaste profissional representa uma característica da própria organização do trabalho (SANTOS; SOARES; CAMPOS, 2007; MARTINES; CHAVES, 2007; AZAMBUJA ET AL., 2007; RIBEIRO; MARTINS, 2011).

Além disso, os trabalhadores da saúde, no cotidiano profissional, são confrontados entre o trabalho prescrito e o real. Conforme assinalam Faria e Araújo (2010, P. 432), o trabalho prescrito

refere-se a tudo aquilo que está posto de antemão (normas, tempo gasto na operação, modo de utilizar ferramentas) e o trabalho real é aquele que acontece efetivamente no cotidiano, longe das condições ideais e idealizadas pelos administradores.

O processo de trabalho ou os "modos específicos de trabalhar" (LAURELL; NORIEGA, 1989, P. 36) assumem características peculiares no setor saúde, pois o "trabalho em saúde é hoje, majoritariamente, um trabalho coletivo institucional" (RIBEIRO; PIRES; BLANK, 2004, P. 438-439).

Os trabalhadores da ESF têm como espaço de atuação territórios diversificados, marcados por importantes vulnerabilidades socioambientais, entendidas, conforme Alves (2006, P. 43), como

a coexistência ou sobreposição espacial entre grupos populacionais muito pobres e com alta privação (vulnerabilidade social) e áreas de risco ou degradação ambiental (vulnerabilidade ambiental).

Em outros termos, a vulnerabilidade socioambiental envolve a sobreposição de múltiplos fatores relacionados, desde a precariedade da infraestrutura básica, alcançando questões ligadas às catástrofes ambientais, como enchentes, por exemplo, com reflexos importantes no processo saúde-doença da população de um modo geral, e, por que não dizer, dos trabalhadores da saúde inseridos nesses contextos.

Desse modo, o processo de trabalho dessas equipes exige que extrapolem o atendimento no âmbito da Unidade de Saúde da Família (USF), haja vista que as práticas assistenciais devem estar voltadas para uma perspectiva de mudanças nos perfis de saúde-doença da coletividade em territórios específicos, sendo importante considerar o contexto socioambiental em que atuam esses profissionais e suas repercussões possíveis sobre as condições de trabalho e saúde dos trabalhadores.

Com efeito, este estudo tem o objetivo de descrever e analisar as condições de trabalho de uma Equipe de Saúde da Família (EqSF), inserida num contexto socioambiental vulnerável, para compreender de que maneira o trabalho, incluindo o ambiente no qual é realizado, representa elemento de satisfação, e, portanto, definidor de saúde, ou elemento de insatisfação, sendo, desse modo, produtor de doenças.

\section{Método}

Trata-se de um estudo de caso, no âmbito de uma abordagem qualitativa, para compreender as condições de trabalho e saúde de trabalhadores de uma EqSF inseridos em ambientes vulneráveis no município de Manaus. Com efeito, o estudo de caso refere-se a "uma análise detalhada de 
um caso individual" que explica a dinâmica do objeto estudado, considerando a unidade social como um todo (GOLDEMBERG, 2004, P. 33).

Por outro lado, Strauss e Corbin (2008, P. 23) definem a "pesquisa qualitativa como qualquer tipo de pesquisa que produza resultados não alcançados através de procedimentos estatísticos ou de outros meios de quantificação", sendo esses os critérios fundamentais para a utilização desse método no presente estudo.

$\mathrm{Na}$ escolha do espaço territorial, considerou-se uma área que apresentasse características de vulnerabilidade socioambiental, com a presença de EqSF. Além das visitas exploratórias a algumas áreas da cidade de Manaus, foi utilizado o trabalho de Freitas et al. (2011, P. 25), a partir do agrupamento dos bairros da cidade de Manaus, considerando algumas características ambientais como "águas poluídas, alagamentos de áreas ocupadas por chuvas intensas, riscos de desabamento e inundações por cheias fluviais".

Desse modo, foi possível perceber que o bairro da Compensa, localizado na zona oeste da cidade, se enquadra, pelo menos, em três dessas situações de vulnerabilidade ambiental e com uma dinâmica populacional intensa.

A população da cidade de Manaus é de 1.802.014 habitantes, ocupando um território de 11.401,092 km², com densidade demográfica de 158,06 hab/ $\mathrm{km}^{2}$, sendo que o bairro da Compensa constitui o quarto mais populoso, com 75.832 habitantes. Contudo, na zona oeste da capital, esse bairro se destaca como o primeiro em termos populacionais (IBGE, 2010).

A Unidade Básica Saúde da Família (UBSF) do estudo de caso foi escolhida por possuir equipe completa na sua composição mínima, cujos trabalhadores atuam há, pelo menos, dois anos no território, assim como por sua localização em área de vulnerabilidade socioambiental, no bairro da Compensa.

A pesquisa de campo foi realizada no período de abril a junho de 2013 , utilizando-se as técnicas da observação participante, entrevistas e grupo focal com 11 profissionais da ESF, sendo eles: médico, enfermeira, técnicos de enfermagem, agentes comunitários de saúde e agente comunitária de endemias.

De acordo com Minayo (2010, P. 274), a observação participante mostra-se uma importante estratégia numa pesquisa do tipo qualitativo, pois "a proximidade com os interlocutores, longe de ser um inconveniente, é uma virtude". É importante frisar que a permanência da pesquisadora com os sujeitos ocorreu por três meses, ininterruptos.

As entrevistas foram orientadas a partir de um roteiro de perguntas que se moldavam ao entendimento de cada entrevistado, pois,

na entrevista, o pesquisador pretende descobrir o que é significativo na vida dos entrevistados, suas percepções e interpretações, suas óticas e cosmovisões, ou seja, sua maneira de interpretar o mundo. (TOBAR; YALOUR, 2001, P. 96).

O grupo focal, como técnica de pesquisa para grupos pequenos, foi utilizado em razão da possibilidade de obter informações a partir das opiniões e atitudes que os trabalhadores expressam na interação com os outros. Nessa interação, buscou-se captar como e por que os sujeitos expressam de determinada maneira, suas perspectivas diante das questões discutidas (MINAYO, 2010; GATTI, 2005).

Foram utilizadas como perguntas norteadoras no grupo focal: Como vocês identificam os problemas de saúde no território? Qual a relação desses problemas com as questões socioambientais no território? Como vocês organizam os processos de trabalho para atuar sobre esses problemas? Como esses problemas repercutem no trabalho e na saúde dos membros da equipe?

Os discursos dos sujeitos foram organizados por categorias profissionais, e os dados 
ordenados a partir do material gravado, que foi transcrito para possibilitar a construção de uma matriz de análise sob três perspectivas: condições de trabalho, condições sociais e ambientais e a relação trabalho/saúde dos profissionais da ESF.

Foram realizadas exaustivas leituras do material, com o intuito de buscar pontos convergentes e divergentes dos discursos entre si, destes com o coletivo e o contexto em que se mostravam. Desse modo, para a análise dos dados, considerou-se como teoria de suporte a hermenêutica-dialética, por possibilitar uma reflexão que se funda na práxis, reunindo, ao mesmo tempo, o processo de compreensão e de crítica da realidade social (MINAYO, 2010).

Para a preservação do anonimato, quando da apresentação dos discursos, optou-se por identificar os sujeitos por meio de siglas correspondentes à sua categoria profissional, nos termos seguintes: Médico (M), Enfermeira (E), Técnico de Enfermagem (Téc. Enf.), Agente Comunitário de Saúde (ACS), Agente de Endemias (Ag. End.).

Este trabalho foi submetido previamente ao Comitê de Ética em Pesquisa da Ensp/ Fiocruz, Escola Nacional de Saúde Pública Sergio Arouca (Ensp), sendo aprovado sob o parecer $n^{\circ} 178.176$, respeitando as normas contidas na Resolução no 466/12, do Conselho Nacional de Saúde (BRASIL, 2013). Também houve submissão à Comissão de Ética em Pesquisa (Coep), da Secretaria Municipal de Saúde (Semsa), como condição para o desenvolvimento do trabalho e para garantir o acesso aos sujeitos da pesquisa.

Os participantes do estudo foram informados sobre os objetivos da pesquisa, com os quais concordaram por meio do Termo de Consentimento Livre e Esclarecido (TCLE), lido, esclarecido e assinado por todos, durante a aplicação das técnicas de entrevistas e grupo focal, sendo permitida a gravação dessas atividades.

\section{Resultados}

\section{Condições de trabalho}

No âmbito da saúde pública de competência do município, que é a Atenção Básica, o bairro da Compensa está sob a tutela do Distrito de Saúde Oeste, com 46 equipes da ESF, sendo que 5 destas encontram-se inativas. Essa rede assistencial apresenta uma distribuição desigual de cobertura de atendimento, sendo importante destacar que a ESF está implantada no município de Manaus desde 1999, contando com 163 equipes ativas, correspondendo a $33 \%$ de cobertura (SEMSA, 2013).

Os trabalhadores da presente pesquisa atuam numa estrutura física de UBSF baseada nos parâmetros arquitetônicos que datam da implantação das UBSF em Manaus, com espaço de, aproximadamente, $32 \mathrm{~m}^{2}$, sendo 1 consultório médico, 1 sala de medicamentos (Farmácia), 1 recepção, 1 banheiro. O consultório é utilizado pelo médico e pela enfermeira de forma alternada. $\mathrm{Na}$ sala de medicamentos há uma copa improvisada, sendo, também, o espaço no qual a enfermeira realiza suas atividades quando o médico está em atendimento. Da mesma forma, esse também é o lugar em que os ACS desenvolvem suas práticas burocráticas, que representam para eles o 'preenchimento de papéis'.

Essa estrutura é considerada antiga se comparada ao novo modelo que a Semsa está implantando em alguns distritos de saúde, o qual apresenta rampa de acesso, banheiro adaptado para portadores de necessidades especiais, uma recepção com cadeiras para aproximadamente 10 pessoas, farmácia, consultórios médico e de enfermagem, medindo em torno de $136 \mathrm{~m}^{2}$.

A faixa etária da equipe de estudo varia entre 32 e 61 anos de idade, com média de 41,6 anos. O tempo de atuação na ESF oscila 
entre 4 e 14 anos de atividade, com maioria possuindo mais de 10 anos de exercício profissional na ESF e mais de 2 anos no território. Há duas espécies de vínculo trabalhista: estatutário (5) e os chamados 'efetivados' (6) por ato administrativo do prefeito, encontrando-se nesta última condição os ACS. A equipe de 11 trabalhadores é composta majoritariamente por mulheres, corroborando o processo de feminização do trabalho em saúde (MACHADO ET AL., 2006; PASTORE; ROSA; HOMEM, 2008).

A equipe de estudo tem sob sua responsabilidade 5.720 pessoas e 1.298 famílias, conforme documentos apresentados por ocasião da observação, referentes ao mês de março/2013. Na prática, os dados revelam 7 microáreas sob a responsabilidade da equipe, embora no trabalho prescrito figurem apenas 5 microáreas de abrangência para aquela equipe.

A precariedade da infraestrutura da UBSF é qualificada pela falta de um banheiro privativo, de utilitários (mesas, cadeiras e armários apresentam-se em péssimas condições de uso) e de equipamentos (como a autoclave, quebrada há anos, o que impede a realização de curativos por falta de material esterilizado). Por isso, o discurso recorrente foi o de que

na realidade, não tem estrutura a casa de saúde! Nós não temos condições de fazer esses procedimentos' [referindo-se a curativos, porque a autoclave está quebrada]. Até mesmo o preventivo! Aqui nessa sala [consultório médico], não está adequada para se colher um preventivo. É realizado, mas nós sabemos e eles [gestão] também sabem lá que não é adequado para isso! O principal problema é a infraestrutura da casa de saúde! Isso daí dificulta muito o nosso trabaIho. (ACS).

No entanto, com uma visão para além do espaço físico, um membro da equipe descreve o que considera também ambiente de trabalho, ou seja, o território no qual atua, informando que é permeado por muitas contradições, marcado pela chamada 'área vermelha', assim denominada por sofrer influência do tráfico de drogas. Contudo, também afirma que, independentemente disso, o trabalho tem que ser realizado: " $E u$ já entrei na casa de traficante, mas eu tenho de ficar cega, surda e muda" (Ag. End.).

O improviso permeia o processo de trabalho diante das precárias condições de infraestrutura relatadas pela equipe, conforme exposto na fala a seguir: "Se não der um jeitinho, a gente não trabalha!” (ACS). Essa afirmação encontra eco em todos os níveis, pois, quando não é possível o chamado 'jeitinho', o trabalho é prejudicado: "Deixo de fazer muitas atribuições porque não tem condições” (Téc. Enf.).

A burocracia, entendida como o excesso de papéis que precisam ser preenchidos, assim como a preocupação dos gestores com o quantitativo, traduzido em produção de serviços, foram as queixas mais recorrentes.

Esses fatores revelaram contribuir para a insatisfação e a falta de reconhecimento do trabalho desses profissionais, porque a rotatividade da população, por exemplo, faz com que se perca produção: "Mas a Semsa não quer saber disso! Estão preocupados com quantidade! Querem só ver o número, a quantidade!” (ACS). Essa situação revela os sentimentos de impotência e ressentimento expressos no discurso de que "as informações não são aproveitadas como deveriam" (ACS). A sentença ganha ainda maior robustez na fala a seguir: "Está faltando muito para que a gente seja reconhecido. Eles [Disa - Distrito de Saúde] não estão ligando muito para o nosso trabalho!" (ACS).

\section{Condições sociais e ambientais}

Do ponto de vista social, o território foi descrito como portador de importantes precariedades, como "as condições de vida das pessoas sem estrutura familiar, que faz com que os adolescentes encontrem o caminho das drogas" 
(ACS). E um lugar de moradia caracterizado como 'um aglomerado': “Temos muito beco, viela [...]” (Téc. Enf.). Além de possuir "população extremamente pobre" (M).

No entanto, o discurso preponderante atribuiu responsabilidade à população que ocupa aquele espaço quanto ao cenário ambiental deteriorado.

Falta de educação por parte dos comunitários. Jogam lixo por tudo que é canto. Oriento, e eles não atendem! (ACS).

É uma questão de higiene, e a pessoa 'não se toca'. (ACS).

Fala-se muito na questão ambiental, mas não tem um trabalho sobre essa questão. O lixo, é a própria população a responsável [...] a população sabe o dia e a hora que o coletor vai passar, mas coloca o lixo a qualquer hora! Falta de consciência! (ACS).

Poderia ter ajuda melhor por parte dos governantes, mas a população também contribui para o descaso! (Téc. Enf.).

O cenário também foi descrito como sendo uma área de risco.

Toda área tem um pouquinho de área de risco! Eu considero uma área de risco, tráfico e violência também! Alguns falam 'área vermelha'. (ACS).

Ambiente meio perigoso! (Ag. End.).

Trabalhamos com uma clientela que é de alto risco na criminalidade, passamos por locais que são linha vermelha do tráfico. (Téc. Enf.).

No que se refere às tecnologias utilizadas para enfrentar as problemáticas do território, todos os discursos convergiram para as visitas domiciliares, juntamente com o que denominam 'orientações', estando nesse bojo as informações sobre o lixo, sobre as quais revelaram não ter preparo formal, tampouco material de suporte. No tocante às chamadas orientações, os profissionais dizem que

não é o suficiente, mas dá para resgatar muitas coisas. (ACS).

Faço orientações caso o usuário aceite ser ajudado. Tem impacto momentâneo. A gente tenta ajudar [referindo-se ao lixo] orientando. (Téc. Enf.).

Oriento, mas, se não atendem, desisto! (ACS).

Essas [pessoas] que não mudam é porque não querem mudar mesmo! Acham que está ótimo! (ACS).

\section{A relação trabalho/saúde dos profis- sionais da ESF}

Os discursos sinalizaram uma percepção sobre o nexo existente entre o trabalho realizado sob as condições socioambientais em que se encontram e a sua repercussão no processo saúde-doença do trabalhador:

Na maioria dos casos, me sinto impotente por não poder executar, fazer pela pessoa. (ACS).

A situação de pobreza toca no profissional, mas são coisas que não dá pra resolver. (ACS).

Teve uma época em que eu não dormia. (ACS).

É importante assinalar que todos os trabalhadores revelaram nunca terem se afastado 
do ambiente laboral por conta dessas situações do contexto. Para corroborar essa afirmação, destacamos o discurso de uma profissional:

Fiquei abalada uma vez, há muito tempo atrás, quando sofri uma denúncia num programa de televisão, mas nem tinha procedência [...]. Mas nunca me afastei por problemas do trabalho. (E).

Ademais, essas situações foram observadas como fazendo parte do cotidiano da equipe, de modo que não interferem diretamente no processo de trabalho:

Tem que se habituar à realidade da comunidade para transformá-la! Na época em que entrei [na ESF], a comunidade vivia em condições piores! (ACS).

Essas condições não interferem nem desmotivam o meu trabalho. Gosto do que faço! A minha área tem tráfico de drogas, prostituição, [...] mas tudo isso não afeta o trabalho, porque todos me conhecem e me respeitam; não mexem comigo! (ACS).

\section{Discussão}

Quanto ao ambiente laboral, considerado pelos trabalhadores a estrutura física da UBSF, na qual estes debruçam suas práticas de trabalho, os dados revelaram que está distante das condições preconizadas pela Portaria $\mathrm{n}^{\circ}$ 2.488/2011, que trata da Política Nacional de Atenção Básica (PNAB), assim como das normas constantes no manual instrutivo que orienta os projetos físicos dos estabelecimentos assistenciais de saúde, no qual são estabelecidos critérios arquitetônicos para o funcionamento e a estrutura física de uma UBSF, que deve servir de referência para acolher a equipe da UBSF (BRASIL, 2002; BRASIL, S.D.).
Embora os trabalhadores convivam com duas espécies de vínculo trabalhista, a condição de serem 'efetivados', no caso dos ACS, não os faz sentirem-se em situação de desvantagem frente aos outros que possuem vínculo estatutário. Aliás, os ACS revelaram que o seu ingresso no serviço público ocorreu por um processo seletivo bastante disputado, apontando para uma conquista meritória estar na ESF.

A precarização dos vínculos trabalhistas, historicamente, surge no cenário nacional em 1995, com a chamada reforma administrativa do Estado, ocasionando a desregulamentação do trabalho, a flexibilização e a responsabilidade dos estados e municípios em assumir a prestação de serviços de saúde (MENDONÇA ET AL., 2010).

No município de Manaus, uma ampla pesquisa tratando sobre o processo de implantação do Programa Saúde da Família (PSF) revelou, entre outros aspectos, que o problema da precarização dos vínculos de trabalho persistia. Além disso, fatores como a

insuficiência de mão de obra e a falta de capacitação dos profissionais foram apontadas como parte das causas da não adoção de rotinas de planejamento local. (SILVA; GARNELO; GIOVANELLA, 2010, P. 598).

Esses dados permanecem bastante atualizados, visto que o último concurso público da Secretaria Municipal de Saúde de Manaus (2012), além de não contemplar ACS, também padeceu de contratação que suprisse o quadro de pessoal na rede de assistência à saúde, assim como revela um planejamento em descompasso com a realidade concreta.

Além disso, a demanda sob responsabilidade dos ACS ultrapassa o preconizado, que assegura 750 pessoas por ACS, e o total máximo de 4000 pessoas para cada equipe, sendo a média recomendada de 3000 pessoas, sem contar que esse número deve levar em conta o grau de vulnerabilidade das famílias presentes no território, ou seja, 
quanto maior o grau de vulnerabilidade, menor deverá ser a quantidade de pessoas por equipe (BRASIL, 2011, ITEM 7, II E III).

Com efeito, os profissionais, em sua maioria, levaram em consideração a estrutura física em si da UBSF, ambiente de trabalho da equipe, embora deva ser considerado também o território de atuação dos profissionais. Desse modo, analisando somente esse aspecto do ambiente de trabalho, a realidade revela que está longe das condições ideais e idealizadas para o desenvolvimento das atividades, corroborando estudo recente que aponta a estrutura física como um dos desafios a serem enfrentados pela Atenção Básica (CAVALCANTI; OLIVEIRA NETO; SOUSA, 2015).

O trabalho em saúde é complexo e muito dinâmico, ensejando um confronto cotidiano entre o trabalho prescrito e o real, sendo o trabalho prescrito aquele estabelecido previamente por meio de normas e ferramentas de trabalho, e o trabalho real o "que acontece efetivamente no cotidiano, longe das condições ideais e idealizadas pelos administradores" (FARIA; ARAÚJO, 2010, P. 432).

De acordo com esse raciocínio, Faria e Araújo (2010) afirmam:

Há uma busca pelo estabelecimento de modelos em todos os níveis de atenção à saúde, o que denota uma aspiração regulatória imposta verticalmente, que se materializa em protocolos de ação, competências profissionais a priori e procedimentos padronizados que se dirigem às partes de um corpo sem história e sem emoção, sem lugar contextualmente circunscrito ou culturalmente perpassado. (FARIA; ARAÚJO, 2010, P. 432).

Estudo abordando a relação trabalho/ saúde revela o desgaste do trabalhador diante das demandas que se apresentam no cotidiano da prática profissional, como $o$ atingimento de metas em detrimento dos problemas que são apresentados pela população, que precisam ser respondidos (SANTOS; SOARES; CAMPOS, 2007).
Por outro lado, a dinâmica da produtividade incorporada pelo setor saúde foi uma característica revelada em todos os discursos, apontando que os trabalhadores atendem às determinações institucionais num processo de cumprimento de metas, sem, contudo, refletir sobre os dados que estão sendo produzidos. Isso se deve à demanda de serviços, mas, também, ao fato de que esses profissionais não são capacitados para entender sobre os indicadores de saúde que estão sob sua responsabilidade.

Ao lado disso, o processo de trabalho revelado pelos profissionais é caracterizado, também, pelo enfrentamento das situações de importantes vulnerabilidades sociais e ambientais, como o tráfico de drogas, a pobreza, o saneamento básico ineficiente e a presença de lixo no peridomicílio. No entanto, essas queixas não constituem problemas que impeçam a execução de suas atividades, logo, não se transformam em necessidades que precisam ser enfrentadas pelos trabalhadores, visto que 'o jeitinho brasileiro', que nada mais é do que o improviso, está incorporado no processo de trabalho da equipe.

O cenário socioambiental, marcado por problemas sociais e deteriorações ambientais importantes, revela-se de uma forma 'naturalizada' pelos profissionais que atuam naquele território. Essa afirmação pode ser apoiada pelo estudo de Frutuoso et al. (2015, P. 341), que destacaram nos discursos de profissionais a "banalização e a naturalização das situações de vulnerabilidades", no contexto estudado.

No que se refere às implicações do cenário socioambiental no processo de trabalho e saúde, importante observar o entendimento de Sato (1996) quando discorre sobre as lógicas do processo saúde-doença para o conhecimento científico e aquele advindo do conhecimento prático, apontando a seguinte diferenciação:

para o trabalhador, a noção de doença tem 
seu núcleo em torno da atividade/inatividade, a doença pode ser vista como forma de evitar o trabalho, como 'desculpa' encobridora de um desejo de afastar-se dele, estando essa visão estreitamente relacionada com os usos que se fazem do corpo. Por outro lado, para a medicina, ela é entendida a partir do estado orgânico, funcional e anatômico do corpo. (SATO, 1996, P. 492).

Nessa perspectiva, os discursos dos trabalhadores inseridos em contextos vulneráveis, na sua maioria, sugerem que não se reconhecem adoecidos, pois não tiveram momento de afastamento laboral em virtude de suas práticas cotidianas. Ou seja, reforçam a ideia de que o adoecimento para esses trabalhadores tem relação com o afastamento, reafirmando que a precariedade das condições de trabalho no âmbito da estrutura física os incapacita muito mais do que o contexto no qual estão inseridos, pois dificulta as atividades laborais cotidianas.

\section{Conclusão}

No percurso deste estudo, buscou-se revelar as condições de trabalho de uma EqSF cujas práticas são desenvolvidas em territórios marcados por importantes vulnerabilidades sociais e ambientais, para compreender a repercussão desses contextos no processo de trabalho e saúde dos trabalhadores.

Os resultados apontam que o processo de trabalho da equipe é moldado pelos limites impostos pelo ambiente de trabalho, este considerado a estrutura física do espaço da UBSF. Dessa forma, estão incluídos como fatores determinantes no processo de trabalho a falta de materiais e insumos necessários para o desenvolvimento das práticas cotidianas desses trabalhadores.

A precariedade das condições de trabalho, traduzida pela falta de materiais e pela infraestrutura inadequada, colabora para o improviso das ações, sinalizando práticas de saúde sem planejamento prévio, com pouca interlocução entre os sujeitos, trabalhadores e usuários do serviço. Na verdade, os dados sinalizam que são reiteradas práticas sanitárias de caráter preventivista para atender muito mais às necessidades institucionais do que produzir saúde no território.

Embora os trabalhadores reconheçam as importantes vulnerabilidades sociais e ambientais no território, a atuação profissional sobre essas vulnerabilidades mostrou-se pouco eficaz, revelando uma realidade presente e determinada por um processo histórico o qual estão impedidos de modificar.

Com efeito, a produção de saúde naquele território sofre influência tanto das condições de infraestrutura inadequadas para a equipe como, também, dos contextos das práticas de saúde desses trabalhadores, que buscam alternativas, como a utilização de tecnologias ditas leves, a exemplo das visitas domiciliares e 'orientações', cujos efeitos são 'momentâneos' sobre a conduta da população.

Ademais, os aspectos sociais e ambientais do território que expõem à vulnerabilidade a população e o trabalhador não impactam diretamente o trabalho e a saúde dos trabalhadores da ESF participantes desta pesquisa, sobretudo os ACS que têm no território seu lugar de vida e trabalho.

Dizendo de outro modo, os trabalhadores reconhecem estar inseridos em contextos socioambientais vulneráveis, contudo, não constituem a razão primeira do descontentamento, mas, sim, a falta de reconhecimento institucional, aliada à infraestrutura inadequada, que estiveram relacionadas aos potenciais fatores de desgaste e adoecimento do trabalhador.

Numa tentativa de avançar, no sentido de evitar listar riscos e agravos advindos das condições de trabalho, a ideia foi apresentar como os trabalhadores produzem saúde nesses territórios vulneráveis, assim como a possível repercussão desses contextos no processo de trabalho e saúde da equipe. 
Em síntese, os profissionais desenvolvem suas práticas em ambientes desfavoráveis, tanto do ponto de vista das condições de trabalho no espaço físico da UBSF quanto dos territórios em que atuam. Como proposta para garantir a promoção de ambientes saudáveis, em consonância com as ações em saúde do trabalhador, apontamos a implementação de um planejamento harmonizado com a realidade concreta desses trabalhadores, o que implica inseri-los nesse processo, assim como implementar ações no âmbito da UBSF, em consonância com o preconizado na PNAB quanto à garantia de infraestrutura necessária à realização das atividades, de forma a minimizar os impactos provocados pelo ambiente no processo de trabalho e saúde desses trabalhadores.

\section{Referências}

\footnotetext{
ALVES, H. P. F. Vulnerabilidade socioambiental na metrópole paulistana: uma análise sociodemográfica das situações de sobreposição espacial de problemas e riscos sociais e ambientais. Revista Brasileira Est. Pop., São Paulo, v. 23, n. 1, p. 43-59, jan./jun. 2006.
}

AZAMBUJA, E. P. et al. Significados do trabalho no processo de viver de trabalhadoras de um programa de saúde da família. Texto Contexto Enferm., Florianópolis, v. 16, n. 1, jan./mar., p. 71-79, 2007.

BRASIL. Ministério da Saúde. Agência Nacional de Vigilância Sanitária. Resolução, $R D C n^{\circ} .50$, de 21 de fevereiro de 2002 [Internet]. Brasília, DF: Ministério da Saúde, 2002. Disponível em: <http://portal.anvisa.gov.br/wps/wcm/connect/ ca36b200474597459fc8df3fbc4c6735/RDC+N\%C
$2 \%$ BA. $+50,+\mathrm{DE}+21+\mathrm{DE}+\mathrm{FEVEREIRO}+\mathrm{DE}+2002$.

pdf?MOD=AJPERES>. Acesso em: 31 jul. 2013.

Ministério da Saúde. Conselho Nacional de Saúde (CNS). Resolução no 466, de 12 de dezembro de 2012. Aprova as diretrizes e normas regulamentadoras de pesquisas envolvendo seres humanos. Diário Oficial [da] União, 2013. Mimeo.

Ministério da Saúde. Secretaria de Atenção à Saúde. Departamento de Atenção Básica. Portaria $n^{\circ} 2.488$, de 21 de outubro de 2011. Aprova a Política Nacional de Atenção Básica, estabelecendo a revisão de diretrizes e normas para a organização da Atenção Básica, para a Estratégia Saúde da Família (ESF) e o Programa de Agentes Comunitários de Saúde (PACS). Brasília, DF: Ministério da Saúde, 2011. Mimeo. 
Ministério da Saúde. Secretaria de Atenção à Saúde. Departamento de Atenção Básica. Saúde mais perto de você. Ampliação de UBS. Manual Instrutivo. Brasília, DF: Ministério da Saúde, [s.d.]. Mimeo.

CAVALCANTI, P. C. S.; OLIVEIRA NETO, A. V.; SOUSA, M. F. Quais são os desafios para a qualificação da Atenção Básica na visão dos gestores municipais? Saúde em Debate, Rio de Janeiro, v. 39, n. 105, p.323-336, abr./jun., 2015.

FARIA, H. X.; ARAÚJO, M. D. Uma perspectiva de análise sobre o processo de trabalho em saúde: produção do cuidado e produção de sujeitos. Saúde Soc., São Paulo, v. 19, n. 2, p. 429-439, 2010.

FREITAS, C. M. et al. Manaus: uma análise ecossistêmica através de indicadores de sustentabilidade ambiental e de saúde. jun., 2011. Mimeo.

FRUTUOSO, M. F. P. et al. Gestão local de saúde em território de vulnerabilidade: motivações e racionalidades. Saúde em Debate, Rio de Janeiro, v. 39, n. 105, p. 337-349, abr./jun. 2015.

GATTI, B. A. Grupo focal na pesquisa em ciências sociais e humanas. Brasília, DF: Líber Livro, 2005.

GOLDENBERG, M. A arte de pesquisar: como fazer pesquisa qualitativa em Ciências Sociais. 8. ed. Rio de Janeiro/São Paulo: Record, 2004.

\section{INSTITUTO BRASILEIRO DE GEOGRAFIA E} ESTATÍSTICA (IBGE).Cidades@. Censo Demográfico 2010 de Manaus, AM. [Internet]. Disponível em: $<$ http://www.ibge.gov.br/cidadesat/xtras/perfil.php? codmun=130260\&search=amazonas $\mid$ manaus $>$. Acesso em: 31 jul. 2013.

LAURELL, A. C.; NORIEGA, M. Processo de produção e saúde: trabalho e desgaste operário. São Paulo: Hucitec, 1989.

MACHADO, M. H. et al. (Org.). Análise da força de trabalho do setor saúde no Brasil: focalizando a feminização. Rio de Janeiro: Observatório de Recursos
Humanos. Escola Nacional de Saúde Pública Sergio Arouca, 2006. Disponível em: <http://www.observarh. org.br/observarh/repertorio/Repertorio_ObservaRH/ ENSPSA-FIOCRUZ/Analise_forca_trabalho.pdf>. Acesso em: 24 jan. 2014.

MARTINES, W. R. V.; CHAVES, E. C. Vulnerabilidade e sofrimento no trabalho do agente comunitário de saúde no programa de saúde da família. Rev. Esc. Enferm. USP, v. 41, n. 3, p. 426-433, set. 2007.

MENDONÇA, M. H. M. et al. Desafios para gestão do trabalho a partir de experiências exitosas de expansão da Estratégia de Saúde da Família. Ciência Saúde Coletiva, v. 15, n. 5, p. 2355-2365, ago. 2010.

MINAYO, M. C. S. O desafio do conhecimento: pesquisa qualitativa em saúde. 12. ed. São Paulo: Hucitec, 2010.

PASTORE, E.; ROSA, L. D.; HOMEM, I. D. Relações de gênero e poder entre trabalhadores da área da saúde. In: SEMINÁRIO INTERNACIONAL FAZENDO GÊNERO - CORPO, VIOLÊNCIA E PODER, 8, Florianópolis, 2008. Disponível em: <http://www.fazendogenero.ufsc. br/8/sts/ST25/Pastore-Rosa-Homem_25.pdf >. Acesso em: 24 jan. 2014.

RIBEIRO, E. M.; PIRES, D.; BLANK, V. L. G. A teorização sobre processo de trabalho em saúde como instrumental para análise do trabalho no Programa Saúde da Família. Cad. Saúde Pública, Rio de Janeiro, v. 20, n. 2, p. 438-446, mar./abr. 2004.

RIBEIRO, S. F. R.; MARTINS, S. T. F. Sofrimento psíquico do trabalhador da Saúde da Família na organização do trabalho. Psicologia em Estudo, Maringá, v. 16, n. 2, p. 241-250, abr./jun. 2011.

SANTOS, V. C.; SOARES, C. B.; CAMPOS, C. M. S. A relação trabalho-saúde de enfermeiros do PSF no município de São Paulo. Rev. Esc. Enferm. USP, São Paulo, v. 41, n. esp., p. 777-781, dez. 2007.

SATO, L. As implicações do conhecimento prático para a vigilância em saúde do trabalhador. Cad. Saúde Púbica, Rio de Janeiro, v. 12, n. 4, p. 489-495, out./dez. 1996. 
SEMSA. SECRETARIA MUNICIPAL DE SAÚDE.

Departamento de Informação, Controle, Avaliação e

Regulação. Sistema de Informação da Atenção Básica

(SIAB), Manaus, 2013. (Mimeo).

SILVA, N. C.; GARNELO, L.; GIOVANELLA, L.

Extensão de cobertura ou reorganização da Atenção

Básica? A trajetória do Programa de Saúde da Família

de Manaus-AM. Saúde Soc., São Paulo, v. 19, n. 3, p. 592-

604, set. 2010.

STRAUSS, A.; CORBIN, J. Pesquisa qualitativa: técnicas e procedimentos para o desenvolvimento de teoria

fundamentada. 2. ed. Porto Alegre: Artmed, 2008.
TOBAR, F.; YALOUR, M. R. Como fazer teses em saúde pública: conselhos e idéias para formular projetos e redigir teses e informes de pesquisas. Rio de Janeiro: Fiocruz, 2001.

Recebido para publicação em agosto de 2015

Versão final em novembro de 2015

Conflito de interesses: inexistente

Suporte financeiro: não houve 